\title{
Potencial antagônico de Trichoderma spp. originários de diferentes agroecossistemas contra Sclerotinia sclerotiorum e Fusarium solani
}

\author{
Gisele Angélica de Souza Louzada ${ }^{1}$, Daniel Diego Costa Carvalho ${ }^{1}$, Sueli Corrêa Marques Mello ${ }^{2,4}$, \\ Murillo Lobo Júnior ${ }^{3}$, Irene Martins ${ }^{2}$ \& Leonardo Minaré Braúna ${ }^{2}$ \\ ${ }^{1}$ Departamento de Fitopatologia, Universidade de Brasília - UnB, \\ CEP 70910-900, Brasília, DF, Brasil \\ ${ }^{2}$ Empresa Brasileira de Pesquisa Agropecuária, Embrapa Recursos Genéticos e Biotecnologia, \\ Parque Estação Biológica, final W-5 norte, CP 02372, CEP 70770-900, Brasília, DF, Brasil \\ ${ }^{3}$ Empresa Brasileira de Pesquisa Agropecuária, Embrapa Arroz e Feijão, \\ Rod. GO-462, Km 12, Fazenda Capivara, Zona Rural, \\ CP 179, CEP 75375-000, Santo Antônio de Goiás, GO, Brasil \\ ${ }^{4}$ Autor para correspondência: Sueli Corrêa Marques Mello, e-mail: smello@cenargen.embrapa.br
}

LOUZADA, G.A.S., CARVALHO, D.D.C., MELLO, S.C.M., LOBO JÚNIOR, M., MARTINS, I. \& BRAÚNA, L.M. Antagonist potential of Trichoderma spp. from distinct agricultural ecosystems against Sclerotinia sclerotiorum and Fusarium solani. Biota Neotrop. 9(3): http://www.biotaneotropica.org.br/v9n3/en/ abstract?article+bn02509032009.

\begin{abstract}
From 40 soil samples collected in the Rio Grande do Sul, Minas Gerais, São Paulo, Bahia, Goiás and Tocantins states, Brazil, a collection of 230 monosporic isolates of Trichoderma spp. was established using TSM selective media. In order to select efficient isolates for biological control, dual culture tests were carried out on PDA media at $20^{\circ} \mathrm{C}$ for Sclerotinia sclerotiorum and at $25^{\circ} \mathrm{C}$ for Fusarium solani f.sp. phaseoli. From the whole collection, 50 isolates presented antagonism against $F$. solani and 111 isolates to $S$. sclerotiorum. The antagonism against both pathogens was found in only $10 \%$ of the isolates. Scanning electron microscopy assessments with seven in vitro selected isolates showed that not all promoted hyperparasitism on the pathogens, suggesting the existence of other mechanisms of antagonism, as antibiosis or competition.
\end{abstract}

Keywords: biological control, pathogen-antagonistic fungus interaction, culture collection of fungi.

LOUZADA, G.A.S., CARVALHO, D.D.C., MELLO, S.C.M., LOBO JÚNIOR, M., MARTINS, I. \& BRAÚNA, L.M. Antagonist potential of Trichoderma spp. from distinct agricultural ecosystems against Sclerotinia sclerotiorum and Fusarium solani. Biota Neotrop. 9(3): http://www.biotaneotropica.org.br/v9n3/en/abstract? inventory+bn02509032009.

Resumo: A partir de 40 amostras de solo, provenientes dos estados do Rio Grande do Sul, Minas Gerais, São Paulo, Bahia, Goiás e Tocantins, uma coleção de 230 isolados monospóricos de Trichoderma spp. foi estabelecida, usando o meio seletivo TSM. Com o objetivo de selecionarem-se isolados com potencial para controle biológico de doenças, foram conduzidos testes de pareamento de culturas em meio BDA, a $20{ }^{\circ} \mathrm{C}$ para Sclerotinia sclerotiorum e a $25^{\circ} \mathrm{C}$ para Fusarium solani f.sp. phaseoli. Antagonismo contra os dois patógenos foi observado em $10 \%$ dos isolados. Avaliações ao microscópio eletrônico de varredura de sete isolados selecionados in vitro mostraram que nem todos promoveram o hiperparasitismo dos patógenos, sugerindo a existência de outros mecanismos de antagonismo, como antibiose ou competição.

Palavras-chave: controle biológico, interação patógeno-antagonista, coleção micológica. 


\section{Introdução}

Medidas de controle de doenças de plantas tais como o uso de variedades resistentes, fungicidas químicos e microrganismos antagonistas podem funcionar bem quando empregadas em conjunto, de modo integrado (Paula Júnior et al. 2008). Em culturas de alta rentabilidade, os fungicidas propiciam a obtenção das fibras e alimentos necessários à população mundial, mas mesmo para essas culturas o controle biológico de fitopatógenos apresenta uma série de vantagens em relação ao uso de fungicidas químicos. Na estratégia de controle biológico clássico, por exemplo, enquanto os fungicidas possuem um efeito temporário e necessitam de repetidas aplicações durante o ciclo das culturas, os agentes de controle biológico são capazes de se estabelecer, colonizar e dispersar no ecossistema (Ávila et al. 2005). Entretanto, o aspecto mais importante a ser considerado, qualquer seja a estratégia utilizada, é que esses agentes biológicos constituem alternativa viável para diminuir o potencial de inóculo de patógenos habitantes do solo, sem trazer danos ao meio ambiente (Mello et al. 2007).

Os fungos do gênero Trichoderma são de grande importância econômica para a agricultura, uma vez que são capazes de atuarem como agentes de controle de doenças de várias plantas cultivadas, promotores de crescimento e indutores de resistência de plantas a doenças (Mohamed \& Haggag 2006, Fortes et al. 2007). Algumas linhagens desses fungos vêm recebendo grande atenção da pesquisa, também, por sua versatilidade de ação. Estas são capazes de produzir enzimas que degradam paredes celulares de outros fungos e produzem também substâncias antifúngicas (antibióticos), apresentam diversidade de estratégias de sobrevivência que as tornam altamente competitivas no ambiente e extraordinária capacidade de proliferação na rizosfera (Melo 1996, Resende et al. 2004). Ademais, certos isolados se mostram resistentes aos fungicidas, característica que os fazem potenciais agentes biorremediadores (Resende et al. 2004). A literatura disponível demonstra que os fungos desse gênero possuem amplas possibilidades para aplicação, tanto no biocontrole de patógenos foliares, quanto no de patógenos radiculares. Entre os vários exemplos, citam-se Sclerotinia sclerotiorum De Bary, Phytophthora spp. De Bary, Cylindrocladium spp. Morgan, Pythium aphanidermatum (Edson) Fitz. e Sclerotium rolfsi Saccardo (Santos \& Dhingra 1982, Smith et al. 1990, Gomes et al. 2001, Patrício et al. 2001, Mello et al. 2007).

A formação de coleções de culturas microbianas é fundamental para o desenvolvimento de programas de controle biológico, uma vez que elas oferecem estoque representativo de amostras de isolados e oportunidade de gerar informações economicamente importantes para a seleção e utilização desses microrganismos (Mello, 2008). O objetivo deste trabalho foi determinar o potencial antagônico de isolados de Trichoderma obtidos a partir de amostras de solos originários de diferentes ecossistemas, contra S. sclerotiorum e Fusarium solani (Mart.) Sacc.

\section{Material e Métodos}

Quarenta amostras de solo foram coletadas em uma área de mata nativa e em várias outras de intensa atividade agrícola, em diferentes regiões dos estados do Rio Grande do Sul, Minas Gerais, São Paulo, Bahia, Goiás e Tocantins (Tabela 1). As amostras foram retiradas a uma profundidade de $0-10 \mathrm{~cm}$ no perfil do solo, e armazenadas em câmara fria até o momento de sua utilização.

Uma massa correspondente a $10 \mathrm{~g}$ de solo de cada amostra foi transferida para frascos de $250 \mathrm{~mL}$, ao qual se adicionaram $90 \mathrm{~mL}$ de água destilada. Após agitação por 40 minutos a 170 rpm, alíquotas de $1 \mathrm{~mL}$ dessas suspensões foram transferidas para outros tubos, procedendo-se as diluições seriadas em água destilada esterilizada.
Para o isolamento, alíquotas das diluições seriadas de $10^{-2}$ e $10^{-3} \mathrm{~g}$ de solo/mL de água foram semeadas em placas de Petri contendo o meio TSM $\left(0,12 \mathrm{~g}\right.$ de $\mathrm{KH}_{2} \mathrm{PO}_{4} ; 0,26 \mathrm{~g}$ de $\mathrm{MgSO}_{4} .7 \mathrm{H}_{2} \mathrm{O} ; 0,26 \mathrm{~g}$ de $\mathrm{KNO}_{3} ; 1,0 \mathrm{~g} \mathrm{de} \mathrm{CaCl}_{2} .2 \mathrm{H}_{2} \mathrm{O} ; 1,0 \mathrm{~g}$ de $\mathrm{Ca}\left(\mathrm{NO}_{3}\right)_{2} ; 1,0 \mathrm{~mL}$ de Igepal; $5 \mathrm{~g}$ de Sacarose; 20,0 $\mathrm{g}$ de ágar e 0,0025 $\mathrm{g}$ de Vinclozolin), conforme Corabi-Adell (2004). As culturas assim preparadas foram incubadas no escuro, sob temperatura ambiente. Após sete dias, colônias típicas de Trichoderma foram transferidas para meio batata-dextrose-ágar (BDA) e mantidas a $25^{\circ} \mathrm{C}$, com fotoperíodo de 12 horas, para obtenção das culturas puras. As características macroscópicas de cada colônia (micélio, pigmentação do meio, esporulação) e microscópicas (fiálides e conídios) dos isolados foram examinadas aos cinco dias, para confirmação do gênero.

Para a preservação dos isolados de Trichoderma obtidos, utilizouse o método descrito por Gonçalves et al. (2007). As culturas foram repicadas para placas contendo meio BDA, porém coberto com papel de filtro previamente esterilizado. Decorridos cinco dias (100\% de colonização das placas), os papéis de filtro colonizados foram transferidos para placas esterilizadas e, então, mantidos em estufa a $27{ }^{\circ} \mathrm{C}$. Após secagem, esses foram recortados e depositados em

Tabela 1. Origem e habitat dos isolados de Trichoderma obtidos a partir de amostras de solo.

Table 1. Geographical origin of Trichoderma isolates obtained from soil samples.

\begin{tabular}{|c|c|c|}
\hline Origem & Cultura & $\begin{array}{c}\text { Número } \\
\text { de isolados } \\
\text { obtidos }\end{array}$ \\
\hline Água Fria - GO & Feijão comum & 8 \\
\hline Água Fria - GO & Soja & 12 \\
\hline Dueré - TO & Pousio & 4 \\
\hline Dueré - TO & $\begin{array}{l}\text { Sorgo consorciado } \\
\text { com B. brizantha }\end{array}$ & 7 \\
\hline Dueré - TO & Milheto & 4 \\
\hline Dueré - TO & $\begin{array}{l}\text { Milheto consorcia- } \\
\text { do com } B \text {. brizantha }\end{array}$ & 7 \\
\hline Dueré - TO & $\begin{array}{l}\text { Milheto consorciado } \\
\text { com B. decumbens }\end{array}$ & 3 \\
\hline Dueré - TO & $\begin{array}{l}\text { Solo arado - } \\
\text { abertura de área }\end{array}$ & 4 \\
\hline Farroupilha - RS & Morango & 6 \\
\hline Guairá - SP & Cana de açúcar & 9 \\
\hline Mucugê - BA & Batata & 12 \\
\hline Mucugê - BA & $\begin{array}{l}\text { Braquiária } \\
\text { (Brachiaria } \\
\text { ruziziensis) }\end{array}$ & 13 \\
\hline Mucugê - BA & Feijão comum & 20 \\
\hline Mucugê - BA & Solo arado & 8 \\
\hline Mucugê - BA & Vegetação nativa & 1 \\
\hline Patos de Minas - MG & Tomate & 42 \\
\hline Rio Verde - GO & Soja & 19 \\
\hline Santo Antônio de Goiás - GO & Milho orgânico & 2 \\
\hline Santo Antônio de Goiás - GO & Feijão orgânico & 10 \\
\hline Santo Antônio de Goiás - GO & Café orgânico & 10 \\
\hline Santo Antônio de Goiás - GO & Banana orgânica & 10 \\
\hline Santo Antônio de Goiás - GO & Mata nativa & 4 \\
\hline Taquarituba - SP & Feijão comum & 15 \\
\hline
\end{tabular}


saquinhos de papel manteiga estéril envolto com papel alumínio, para o subseqüente armazenamento a $-20^{\circ} \mathrm{C}$.

Os isolados de $S$. sclerotiorum e $F$. solani foram obtidos, respectivamente, de planta de feijoeiro comum (Phaseolus vulgaris L.) e de amostras de solo procedentes de área de cultivo de feijoeiro com histórico de ocorrência das doenças. Para F. solani, o solo foi submetido à diluição em série e plaqueamento em meio semi-seletivo de Nash-Snyder, com as características confirmadas de acordo com Leslie \& Summerell (2006). Em seguida, os isolados foram repicados para meio BDA e incubados em BOD (Fanem, Modelo 347) à temperatura de $20-25{ }^{\circ} \mathrm{C}$, com fotoperíodo de 12 horas. Para obtenção dos isolados de $S$. sclerotiorum, escleródios foram desinfestados superficialmente com álcool 70\% (1 minuto), imersos em hipoclorito de sódio 3\% (1 minuto) e lavados por três vezes com água destilada autoclavada, seguindo-se o plaqueamento em meio BDA. Após a germinação da estrutura de resistência, o micélio foi mantido em meio BDA. Os patógenos foram re-inoculados em plantas de feijão comum, para a confirmação da patogenicidade.

$\mathrm{O}$ antagonismo dos isolados de Trichoderma contra ambos os patógenos foi avaliado pelo método de culturas pareadas, conforme descrito por Mello et al. (2007). Discos de ágar contendo micélio de S. sclerotiorum e do antagonista (5 $\mathrm{mm}$ de diâmetro) foram retirados de colônias com três dias de cultivo e depositados, simultaneamente, em extremidades opostas das placas de Petri, contendo meio BDA solidificado. Igual procedimento foi adotado para os testes com F. solani, exceto que o tempo de repicagem do patógeno foi de dois dias antes do antagonista. As placas foram incubadas em BOD a 20 e $25^{\circ} \mathrm{C}$ para favorecimento dos patógenos S. sclerotiorum e F. solani, respectivamente (Bardin \& Huang 2001).

Após sete dias de cultivo, avaliou-se o crescimento micelial dos fungos, conforme escala proposta por Bell et al. (1982), modificada. De acordo com essa escala, os isolados foram classificados como: nota 1, crescimento de Trichoderma sobre o patógeno, ocupando toda a superfície do meio; nota 1,5 - crescimento de Trichoderma, ocupando 7/8 da superfície do meio; nota 2 - crescimento de Trichoderma, ocupando mais de 2/3 da superfície do meio; nota 2,5 - crescimento de Trichoderma, ocupando 5/8 da superfície do meio; nota 3 - crescimento de Trichoderma, ocupando aproximadamente metade da superfície do meio; nota 3,5 - crescimento de Trichoderma, ocupando 3/8 da superfície do meio; nota 4 - crescimento de Trichoderma, ocupando $1 / 3$ da superfície do meio e nota 5 - ausência de crescimento de Trichoderma, patógeno ocupando toda a superfície do meio. Os experimentos foram realizados com três repetições. Considerou-se o isolado como antagônico ou eficiente quando sua nota era menor ou igual a 3,0 .

Para estudo da interação entre isolados de Trichoderma e dos patógenos, pela técnica de microscopia eletrônica de varredura (MEV), foram utilizadas amostras provenientes do pareamento de culturas realizado com sete isolados de Trichoderma. Para tanto, discos de
BDA (5 mm de diâmetro) provenientes de áreas do confronto entre as colônias de sete isolados de Trichoderma spp. (cinco isolados com forte atividade antagônica: 26/01, 05/01, 15/05, 13/03 e 04/10; dois isolados inativos nos testes de cultura pareada: 03/06 e 50/02) e dos patógenos ( $F$. solani e $S$. sclerotiorum) foram removidos e submetidos ao procedimento descrito por Bossola \& Russel (1998), adaptado por Alves (2004), a seguir: tratamento com solução fixadora (glutaraldeído $2 \%$ e paraformaldeído $2 \%$, em tampão cacodilato $0,05 \mathrm{M}$ a $\mathrm{pH} 7,2$ ) para fixação a $4{ }^{\circ} \mathrm{C}$ durante 24 horas, seguido de 4 lavagens com tampão cacodilato $0,05 \mathrm{M}(\mathrm{pH} 7,2)$ e pós-fixados durante 1 hora a $4{ }^{\circ} \mathrm{C}$ com tetróxido de ósmio $\left(\mathrm{OsO}_{4}\right) 1 \%$ em tampão cacodilato $0,01 \mathrm{M}$ (pH 7,2). Em seguida, as amostras foram lavadas três vezes com água destilada, e desidratadas em gradiente crescente de álcool etílico (10, 20, 30, 50, 70, 80, 90, 95 e 100\%). Para secagem ao ponto crítico, utilizou-se dióxido de carbono no secador Elmitech Critical Point Drayer K850. As amostras foram, então, montadas sobre "stubs" de alumínio e metalizadas com ouro $(20 \mathrm{~nm})$ em evaporador de ouro Elmitech k 550. As visualizações foram realizadas ao microscópio eletrônico ZEISS ${ }^{\circledast}$ DSM 962, com o objetivo de observar o enrolamento de hifas dos isolados de Trichoderma spp. sobre os patógenos. Todas as repetições de pareamento de culturas representativas dos sete isolados do antagonista foram incluídas neste estudo.

\section{Resultados}

Identificaram-se 230 isolados como pertencentes ao gênero Trichoderma. Destes, 50 isolados inibiram o crescimento micelial de $F$. solani e 111 de $S$. sclerotiorum, pelo teste de pareamento de culturas (notas menores que 3), conforme resumido na Tabela 2. $\mathrm{O}$ antagonismo contra os dois patógenos foi observado em $10 \%$ dos isolados (24 isolados). Praticamente metade dos isolados de Trichoderma (52\%) não apresentaram efeito inibitório contra $F$. solani (notas superiores a 3), enquanto para $S$. sclerotiorum, esse índice foi de apenas $14 \%$.

Após processamento para MEV das amostras representativas dos isolados 03/06, 04/10, 05/01, 13/03, 15/05, 26/01 e 50/02 de Trichoderma, obtidas do pareamento de culturas, interações entre patógeno e antagonista foram observadas apenas para os isolados 04/10, 05/01 e 50/02 (Figura 1).

\section{Discussão}

Embora eficientes contra os dois patógenos nos testes de cultura pareada, os isolados 13/03, 15/05 (ambos com origem em Patos de Minas, MG) e 26/01 (Dueré, TO) não revelaram qualquer tipo parasitismo direto, pelos exames das amostras realizados ao MEV. Esse resultado corrobora dados obtidos por outros autores, evidenciando que, além do parasitismo direto, outros mecanismos podem estar envolvidos na ação antagonista de fungos do gênero Trichoderma,

Tabela 2. Potencial antagônico de Trichoderma spp. contra F. solani e S. sclerotiorum segundo escala de Bell et al. (1982) ao $7^{\circ}$ dia de cultivo pareado.

Table 2. Antagonic potential of Trichoderma spp. against F. solani and S. sclerotiorum according to Bell's scale (Bell et al. 1982) with 7 days of dual culture.

\begin{tabular}{ccc}
\hline $\begin{array}{c}\text { Notas de acordo com a escala de Bell et al. (1982) } \\
\text { atribuídas aos isolados de Trichoderma spp. } \\
\text { quanto ao antagonismo ao } \mathbf{7}^{\mathbf{0}} \text { dia* }^{*}\end{array}$ & \multicolumn{2}{c}{$\begin{array}{c}\text { Quantidade de isolados de Trichoderma } \\
\text { avaliados contra os patógenos }\end{array}$} \\
\cline { 2 - 3 } Menor que 3 & F. solani & 111 \\
3 & 50 & 70 \\
Maior que 3 & 110 & 31 \\
\hline
\end{tabular}

Quantidade de isolados de Trichoderma avaliados contra os patógenos

\footnotetext{
*Nota 3: Trichoderma ocupa aproximadamente metade da superfície da placa de Petri.
}

*Note 3: Trichoderma grown on $50 \%$ of Petri dish surface. 

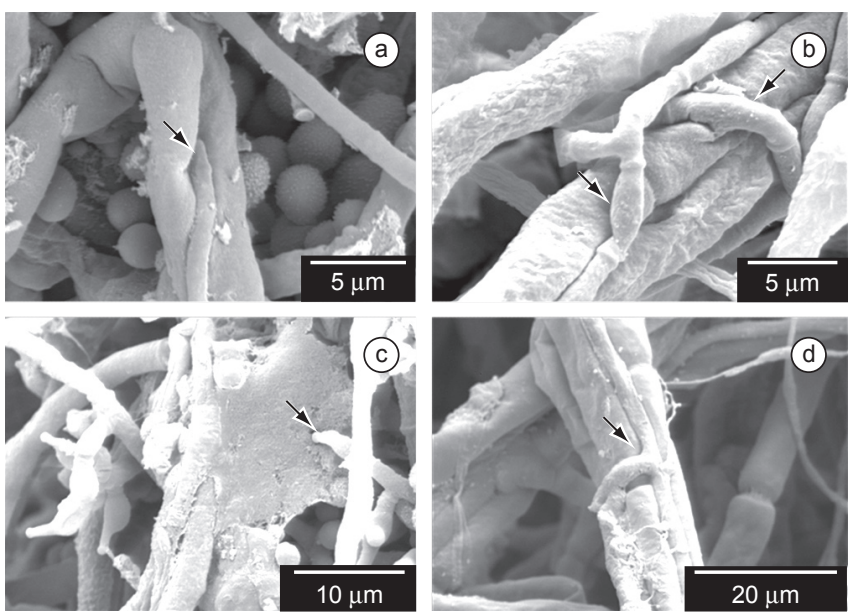

Figura 1. Eletromicrografia de varredura das interações entre Trichoderma spp. e os patógenos (Fusarium solani e Sclerotinia sclerotiorum): a) Hifa de Trichoderma spp., isolado 04/10, aparentemente penetrando a hifa de F. solani; b) Enrolamento de hifas de Trichoderma spp., isolado 50/02, em hifas de F. solani; c) Aglomerado de hifas de S. sclerotiorum sendo parasitado por uma hifa de Trichoderma spp. (isolado 05/01); d) Parasitismo de hifas de Trichoderma spp., isolado 50/02, sobre $S$. sclerotiorum. As setas destacam as etapas de hiperparasitismo no hospedeiro: a, c) penetração, b) enrolamento e d) hifas paralelas.

Figure 1. Scanning electron micrographs of interactions between Trichoderma spp. and pathogen (Fusarium solani and Sclerotinia sclerotiorum): a) Trichoderma hyphae, isolate $04 / 10$, causing an apparent penetration in F. solani hyphae; b) Hyphae of Trichoderma, isolate 50/02, rolled-up the F. solani hyphae; c) S. sclerotiorum hyphae complex colonized by the Trichoderma spp. hyphae, isolate 05/01; d) Parasitism of Trichoderma spp., isolate 50/02, on S. sclerotiorum. The arrows shown the hyperparasitism stages on the host: a, c) penetration, b) rolling-up and d) parallel hyphae.

tais como antibiose e competição (Benhamou \& Chet 1996, Fravel 2005).

O primeiro trabalho que descreveu um isolado de Trichoderma como agente de biocontrole foi publicado por Weindling (1932). Desde então, várias espécies do gênero tem sido pesquisadas e desenvolvidas como agentes de biocontrole para diversos patógenos (Mello et al. 2007). Com este trabalho, foram obtidos dados que indicam o potencial antagonista de isolados de Trichoderma provenientes de diferentes regiões brasileiras, contra dois patógenos distintos. De fato, a literatura refere-se a espécies de Trichoderma como parasitas de uma ampla gama de fitopatógenos, a despeito da maioria dos agentes empregados no biocontrole de doenças de plantas apresentarem certo grau de especialização. Entretanto, o nível de controle pode variar, a depender do isolado e de sua adaptação às condições bióticas e abióticas específicas, dentro e entre espécies de Trichoderma (Dennis \& Webster 1971a, b). Wells et al. (1972), por sua vez, observaram que espécies de Trichoderma podem ser diferencialmente seletivas contra diferentes fungos. Neste trabalho, vários isolados $(10 \%$ do total) se revelaram altamente efetivos in vitro contra dois patógenos que atacam culturas economicamente importantes. Esse potencial necessita agora ser examinado por meio de bioensaios conduzidos sob condições controladas e de campo.

No presente estudo, entre as 23 amostras de solo utilizadas, 22 eram provenientes de áreas cultivadas. Portanto, a grande maioria dos isolados fora submetidos ao contato com patógenos e distúrbios como preparo do solo e aplicação de insumos. De forma oposta a este trabalho, Corabi-Adell (2004) trabalhou com isolados de Trichoderma provenientes de áreas nativas ou com reduzido efeito antrópico, e verificou maior percentual de isolados potencialmente ativos contra fitopatógenos nos testes in vitro, de aproximadamente $80 \%$. Aparentemente, não há outros relatos em literatura que informem sobre a perda de diversidade de Trichoderma spp. com o uso agrícola contínuo de solos ou a possível relação de tais distúrbios com a redução da frequiência do antagonismo a patógenos. Além disso, os resultados obtidos neste trabalho não apresentaram correlação com a origem da amostra ou espécie vegetal cultivada.

O enrolamento de hifas de $F$. solani e $S$. sclerotiorum por Trichoderma (isolado 50/02 - proveniente de Rio Verde, GO) foi observado em MEV, conforme documentado nas Figuras $1 \mathrm{~b}$ e 1d, respectivamente. Para o isolado 05/01 (Mucugê, BA), confirmou-se a atividade parasítica in vitro contra $S$. sclerotiorum (Figura 1c). Já o isolado 04/10 (Mucugê, BA), que foi ativo contra os dois patógenos em cultura pareada, apresentou capacidade parasítica apenas nas amostras do pareamento com F. solani (Figura 1a). Os três tipos de interações verificadas, penetração (Figura 1a e 1c), enrolamento (Figura 1b) e desenvolvimento de hifas paralelas (Figura 1d), podem ser interpretados como ação hiperparasítica (Agrios 2005). Os resultados obtidos em MEV para os isolados 04/10, 05/01 e 50/02 estão de acordo com relatos de Inbar et al. (1996) e Ávila et al. (2005), que verificaram por meio de microscopia eletrônica de varredura e de luz, interações semelhantes entre hifas de T. harzianum e S. sclerotiorum, em condições de cultivo simultâneo in vitro.

Este trabalho demonstrou a importância de se estabelecer coleções de culturas de Trichoderma spp., que sejam representativas de uma ampla área geográfica, pois bons antagonistas estão dispersos por diferentes regiões do país. Embora a grande maioria dos isolados de Trichoderma obtidos tenha sido considerada ineficiente na inibição do crescimento micelial dos dois patógenos testados, o presente trabalho gerou um número considerável de novas culturas fúngicas. A partir da incorporação dessas culturas às coleções de microrganismos da Embrapa, esses novos isolados passam a fazer parte do patrimônio de recursos genéticos microbianos, preservado no país. Vale salientar que a formação de coleções de culturas é de real importância pela possibilidade de se disponibilizar esses organismos para estudos e testes pela comunidade científica, o que poderá originar uma infinidade de produtos e processos de interesse da sociedade.

Finalmente, cabe lembrar que excelentes resultados com antagonistas obtidos in vitro podem não ser confirmados em condições de campo, já que esses organismos estão sujeitos às reações diferenciais do hospedeiro e do ambiente (Harman 1991). Um total de 24 isolados de Trichoderma sp. foram selecionados após pareamento de culturas contra os patógenos F. solani e $S$. sclerotiorum, incluindo o isolado 50/02 (hiperparasita, conforme demonstrado em MEV). Além dos isolados mencionados acima, os isolados que se mostraram ineficientes ou de moderada eficiência nos testes realizados, deverão ser mantidos em condições seguras, para uso futuro em estudos visando ao biocontrole de outros patógenos, bem como para prospecção da produção de enzimas e outros metabólitos de interesse agroindustrial.

\section{Agradecimento}

Os autores agradecem ao Conselho Nacional de Desenvolvimento Científico e Tecnológico (CNPq) por uma bolsa de mestrado e outra de doutorado.

\section{Referências}

AGRIOS, G.N. 2005. Plant Pathology. 5 ed. Elsevier academic press, New York, 922p.

ALVES, E. 2004. Curso introdutório à microscopia eletrônica de varredura. UFLA/FAEPE, Lavras, 43 p. 
ÁVILA, Z.R., CARVALHO, S.S., BRAÚNA, L.M., GOMES, D.M.P.A., SILVA, M.C.F. \& MELLO, S.C.M. 2005. Seleção de isolados de Trichoderma spp. antagônicos a Sclerotium rolfsi e Sclerotinia sclerotiorum. Embrapa Recursos Genéticos, Brasília. 30p. (Boletim Técnico de Desenvolvimento e Pesquisa 177).

BARDIN, S.D. \& HUANG, H.C. 2001. Research on biology and control of Sclerotinia diseases in Canada. Can. J. Plant Pathol. 23 (1):88-98.

BELL, D.K., WELLS, H.D. \& MARKHAM, C. R. 1982. In vitro antagonism of Trichoderma species against six fungal plant pathogens. Phytopathology 72(4):379-382.

BENHAMOU, N. \& CHET, I. 1996. Parasitism de Sclerotia of Sclerotium rolfsii by Trichoderma harzianum: ultrastructural and cytochemical aspects of the interaction. Phytopathology 86(4):405-416.

BOSSOLA, J.J. \& RUSSEL, L.D. 1998. Electron Microscopy. 2 ed. Jones and Bartlett Publishers, Boston, 670p.

CORABI-ADELL, C. 2004. Biodiversidade do gênero Trichoderma (HYPOCREALES - FUNGI) mediante técnicas moleculares e análise ecofisiográfica. Tese de Doutorado, Instituto de Biociências, Universidade Estadual de São Paulo, Rio Claro, 220 p.

DENNIS, C. \& WEBSTER, J. 1971a. Antagonistic properties of speciesgroups of Trichoderma I. Production of non-volatile antibiotics. T. Brit. Mycol. Soc. 57(1):25-39.

DENNIS, C. \& WEBSTER, J. 1971b. Antagonistic properties of speciesgroups of Trichoderma III. Hyphal interactions. T. Brit. Mycol. Soc. 57(3):363-369.

FORTES, F.O., SILVA, A.C.F., ALMANÇA, M.A.K. \& TEDESCO, S.B. 2007. Promoção de enraizamento de microestacas de um clone de Eucalyptus sp. por Trichoderma spp. Rev. Árvore 31(2):221-228.

FRAVEL, D.R. 2005. Commercialization and implementation of biocontrol. Ann. Rev. Phytopathol. 43(1):337-359.

GOMES, N.S.B., GRIGOLLET JUNIOR, A. \& AUER, C.G. 2001. Seleção de antagonistas para controle de Cylindrocladium spathulatum em erva mate. Bol. Pesq. Fl. 43(1):123-128.

GONÇALVES, R.C., ALFENAS, A.C. \& MAFIA, R.G. 2007. Armazenamento de microrganismos em cultura com ênfase em fungos fitopatogênicos. In: Métodos em Fitopatologia (A.C. ALFENAS \& R.G. MAFIA, eds). Universidade Federal de Viçosa, Viçosa, 382p.

HARMAN, G.E. 1991. Seed treatment for biological control of plant disease. Crop Prot. 10(3):166-171.

INBAR, J., MENENDEZ, A. \& CHET, I. 1996. Hyphal interaction between Trichoderma harzianum and Sclerotinia sclerotiorum and its role in biological control. Soil Biol. Biochem. 28(6):757-763.
LESLIE, J.F. \& SUMMERELL, B.A. 2006. The Fusarium Laboratory Manual. Blackwell Professional Publishing, Ames, Iowa. 385 p.

MELLO, S.C.M. 2008. Recursos genéticos de microrganismos. In: Agricultura Tropical: quatro décadas de inovações tecnológicas, institucional e políticas. v. 2. (A.C.S. ALBUQUERQUE \& A.G. SILVA). Embrapa Informação Tecnológica, Brasília, 700p.

MELLO, S.C.M., ÁVILA, Z.R., BRAÚNA, L.M., PÁDUA, R.R. \& GOMES, D. 2007. Cepas de Trichoderma para el control biológico de Sclerotium rolfsii Sacc. Fitosanidad 11(1):3-9.

MELO, I.S. 1996. Trichoderma e Gliocladium como bioprotetores de plantas. Revis. Anu. Patol. Plantas 4(1):261-295.

MOHAMED, H.A.L.A. \& HAGGAG, W.M. 2006. Biocontrol potential of salinity tolerant mutants of Trichoderma harzianum against Fusarium oxysporum. Braz. J. Microbiol. 37(2):181-191.

PATRÍCIO, F.R.A., KIMATI, H. \& BARROS, B.C. 2001. Seleção de isolados de Trichoderma spp. Antagônicos a Pythium aphanidermatum e Rhizoctonia solani. Summa Phytopathol. 27(2):223-229.

PAULA JÚNIOR, T.J., VIEIRA, R.F., TEIXEIRA, H., COELHO, R.R., CARNEIRO, J.E.S., ANDRADE, M.J.B. \& REZENDE, A.M. 2008. Informações técnicas para o cultivo do feijoeiro-comum na região central brasileira: 2007-2009. EPAMIG-CTZM, Viçosa, 180p.

RESENDE, M.L., OLIVEIRA, J.A., GUIMARÃES, R.M., VON, R.G.P. \& VIEIRA, A.R. 2004. Inoculação de sementes de milho utilizando o Trichoderma harzianum como promotor de crescimento. Cienc. Agrotec. 28(4):793-798.

SANTOS, A.F. \& DHINGRA, O.D. 1982. Pathogenicity of Trichoderma spp. on the sclerotia of Sclerotinia Sclerotiorum. Can. J. Botany 60(4):472-475.

SMITH, V.L., WILCOX, W.F. \& HARMAN, G.E. 1990. Potential for biological control of Phytophthora root and crown rots of apple by Trichoderma and Gliocladium spp. Phytopathology 80(9):880-885.

WEINDLING, R. 1932. Trichoderma lignorum as a parasite of others soil fungi. Phytopathology 22(8):837-845.

WELLS, H.D., BELL, D.K. \& JAWORSKI, C.A. 1972. Efficacy of Trichoderma harzianum as a biocontrol agent for Sclerotium rolsfsii. Phytopathology 62(4):442-447.

Recebido em 08/04/09 Versão reformulada recebida em 25/06/09 Publicado em 05/07/09 